\title{
A study of the decision outcomes and financial costs of multidisciplinary team meetings (MDMs) in oncology
}

\author{
P B De leso ${ }^{1}$, J I Coward ${ }^{1,2}$, I Letsa ${ }^{1}$, U Schick ${ }^{1}$, M Nandhabalan ${ }^{1}$, S Frentzas ${ }^{1}$ and M E Gore ${ }^{\star, 1}$ \\ ${ }^{1}$ Royal Marsden NHS Foundation Trust, Fulham Road, London SW3 6JJ, UK and ${ }^{2}$ Inflammation \& Cancer Therapeutics Group, \\ Mater Research, Level 4 Translational Research Institute, Woolloongabba, Brisbane, Queensland 4102, Australia
}

Background: The benefits of multidisciplinary working in oncology are now accepted as the norm and widely accepted as being pivotal to the delivery of optimal cancer care. Central to this are the multidisciplinary meetings (MDMs) and we have evaluated decision outcomes and financial costs of these.

Methods: We reviewed the electronic patient records of 551 newly referred patients, discussed at 14 tumour site-specific MDMs for adult solid tumours and lymphoma (paediatric oncology and acute leukaemia were excluded) over a 1-month period, a total of 52 MDMs were studied. In addition, the records of a further 81 patients from 10 different MDMs were reviewed where the treating consultant had clearly recorded their opinion of how the patient should be managed and this was compared with the final MDM's consensus view. We also costed the MDMs utilising two different methodologies.

Results: The mean age of the 551 patients in the study was 62 years. In all, 536 (97.3\%) patients were treatment naive before MDM discussion and $15(2.7 \%)$ had prior treatment. Median time to treatment after the MDM was 16 days. In 535 (97.1\%) cases, the MDM discussions were clearly documented, 16 (2.9\%) were not clearly documented. In total, 319 (57.9\%) patients were discussed once, and 232 (42.1\%) were re-discussed (one to six occasions). In 62 (12.7\%) patients, there were delays in MDM discussion, 30 (48.4\%) were related to radiology, 26 (41.9\%) to histopathology and $6(9.7 \%)$ a combination of both. Adherence to the MDM management plan decision occurred 503 times (91.3\%) with 48 (8.7\%) deviations. In the smaller cohort of 81 patients, the consultant management plan and MDM consensus was compatible 71 (87.6\%) times. On four occasions, there were major alterations in management while six were minor. The cost per month of our MDMs ranged from $£ 2192$ to $£ 10050$ (median $£ 5136$ ) with total cost of $£ 80850$ per month and the cost per new patient discussed was $£ 415$.

Conclusion: Adherence to MDM decisions by health-care professionals occurs in the majority of patients. MDMs are costly, which may have relevance in the currently challenged health-care financial environment. There is a need to improve MDM efficiency without losing the considerable benefits associated with regular MDMs.

The National Health Service (NHS) Cancer plan in 2000 aimed to eliminate the inequalities of care that had been identified by the Calman-Hine report (Calman-Hine Report, 'Expert Advisory Group on Cancer, 1995 Calman-Hine Report, 'Expert Advisory Group on Cancer. A policy framework for commissioning cancer services: a report to the chief medical officers of England and Wales,' Department of Health, 1995) and set the scene for formalising management decisions for the care of cancer patients in the United Kingdom (Department of Health, 2000). The first wave of tumour-specific improving outcomes guidance documents that were published in the late 1990s mandated that all cases of cancer should be managed by multidisciplinary teams and all new cases discussed by such teams at multidisciplinary team meetings (MDM) (NHS executive, 1996). The UK National Institute for 
Health and Clinical Excellence (NICE) has consistently highlighted this model as being integral for the delivery of good cancer services (NICE, 2006).

Multidisciplinary team meetings appear to have reduced the incidence of more questionable practices and also facilitate the development and implementation of evidence-based decisions (Forrest et al, 2005; Stephens et al, 2006; Mazzaferro and Majno, 2011). They have become an opportunity for colleagues to exchange ideas and support one another in relation to the management of difficult clinical problems. There are several factors within the MDM dynamic that facilitate optimal decision making but the presence of all members of the specialist multidisciplinary and multi-professional team is perhaps the most important. Good communication between team members with open and non-judgemental discussion is vital to optimising the process. The quality of the leadership of MDMs is of central importance to ensure a true consensus is reached in difficult cases, documentation of the discussion is made and that the final decision is clear and unambiguous for each individual patient.

The processes that have grown up and evolved around the MDM are now starting to be questioned. Parts of the process are seen as being unnecessarily bureaucratic and fast becoming a 'tick box exercise', with the danger that the original aims of MDMs are lost. There is a paucity of publications in the literature regarding the functioning of cancer MDMs as they relate patient outcomes (Junor et al, 1994; Birchall et al, 2004; Houssami and Sainsbury, 2006). In addition, there has been no examination of the cost effectiveness of MDMs and this needs to be performed as part of the current imperative to evaluate all health-care processes in relation to available resources.

In order to address some of the issues relating to the effectiveness and efficiency of MDMs, we performed a study assessing the functioning and outcomes of 14 MDMs across 11 tumour types at our institution. We analysed the decisions made, attendance at meetings, clarity of documentation, costs, case re-discussions and deviations from MDM decisions. In addition, we reviewed cases where the responsible consultant had clearly documented their proposed treatment plan before the MDM in order to determine the frequency of discordance between the view of the consultant and the MDM.

\section{PATIENTS AND METHODS}

Data were collected on all new patients (newly referred with primary or relapsed disease) discussed for the first time at the MDMs within our tumour site-specific clinical units at the Royal Marsden NHS Foundation Trust over a 1-month period. The study involved MDMs pertaining to the care of patients with adult solid tumours and lymphoma. Those MDMs dealing with paediatric oncology and acute leukaemia were excluded. The study was approved by the Clinical Audit Committee of our institution.

Five hundred fifty-one patients were identified from the MDM patient lists, which are generated before each meeting. Data were extracted from patient's individual electronic record. These data included time from MDM discussion to initiation of treatment, instances of treatment initiation before MDM discussion, clarity of documentation of MDM decision, number of case re-discussions, reasons for delay in discussion or decision making relating to pathology or radiology and the cost of the individual MDMs. Relevant data were captured up to and including 1 year following initial MDM presentation.

In a separate review over subsequent months, we examined the medical records of 200 patients discussed at 10 different MDMs. We found 81 patients under the care of 29 different consultants who had a clear and unequivocal management plan documented by the patient's consultant before the MDM discussion. We documented the frequency of discordance between the consultant's management or treatment plan before the MDM and the subsequent decision of that MDM. Data on discordance in relation to follow-up, investigation and subsequent treatment received were collected. Alterations in patient management were described as either major or minor. Major alterations included a radical change to overall treatment because of changes in diagnosis, disease stage or patient circumstance. There were no instances of a radical change in treatment simply because of differences of opinion between multidisciplinary team members. Minor alterations included changes to the type and frequency of follow-up, small additions to well-established treatment guidelines and referral to other disciplines within the multidisciplinary team for further detailed explanation of the management plan.

We utilised two methodologies to assess the cost of the MDMs. Costings for all 14 MDMs were calculated on the number of Royal Marsden NHS foundation trust core medical staff present based on attendance records. Core members including surgeons, medical oncologists, clinical oncologists, radiologists, histopathologists, clinical nurse specialists and MDM coordinators were included in the calculations and their numbers per MDM are seen in Table 1. The Royal Marsden Hospital Finance Department provided hourly salary details of all participants based on 2011/2012 figures. The hourly figure was then multiplied by the median running time of each MDM, with the final amount calculated for the month. Overheads including heating, lighting and information technology support were also factored in at a rate of $12.6 \%$ of the total cost.

The costs relating to consultants, junior staff and nurses from other hospitals who were present as part of the tumour site-specific cancer network were not included in the cost analysis. The number of such colleagues varied between tumour-specific MDMs but in at least one case was as high as 14 .

A second, more in depth costing analysis was performed for four MDMs namely those for breast, upper gastrointestinal, lower gastrointestinal and gynaecological cancer. In this analysis, the time required for core members, particularly histopathologists and radiologists, to prepare for the MDM was costed as well as the time of active MDM participation. Each participant was asked to provide data on the former. Once again the salaries were based on 2011/2012 figures and overheads costed at a rate of $12.6 \%$.

\section{RESULTS}

There were 551 new patients discussed at $52 \mathrm{MDMs}$ in the month of June 2010 (Table 2). Patients had a median age of 62 years with the majority referred by surgeons (53.9\% of patients). Medical oncologists referred $29.6 \%$ of patients and clinical oncologists, $14.5 \%$. The remaining $1.9 \%$ were referred for discussion by geneticists, haematologists or dermatologists.

In all, 536 patients $(97.3 \%)$ commenced treatment after MDM discussion. The median time from discussion at the MDM to treatment was 16 days. Fifteen patients (2.7\%) commenced treatment before presentation of their case to the MDM.

The discussion and final consensus of the MDM was clearly documented in the electronic patient record of 535 out of the 551 patients (97.1\%). In 16 patients (2.9\%), the MDM discussion/ decisions were not clearly recorded.

The majority of the 551 patients (319 patients, 57.9\%) were discussed at only one MDM but a surprisingly large minority, 232 patients $(42.1 \%)$ were discussed more than once at the same tumour site-specific MDM. We therefore went on to analyse these patients further and found that 14 patients were discussed at three 
Table 1. Core member attendance numbers per MDM

Core members

\begin{tabular}{|c|c|c|c|c|c|c|c|c|c|}
\hline Tumour site & $\begin{array}{l}\text { Medical } \\
\text { oncologist }\end{array}$ & $\begin{array}{c}\text { Clinical } \\
\text { oncologist }\end{array}$ & Surgeon & Haematologist & CNS & Radiologist & Pathologist & $\begin{array}{c}\text { MDM } \\
\text { coordinator }\end{array}$ & Total \\
\hline Gynaecology & 2 & 2 & 4 & 0 & 3 & 1 & 1 & 1 & 14 \\
\hline Renal & 2 & 1 & 1 & 0 & 1 & 1 & 1 & 1 & 8 \\
\hline Melanoma & 2 & 1 & 2 & 0 & 2 & 1 & 2 & 1 & 11 \\
\hline Lung & 1 & 3 & 1 & 0 & 1 & 1 & 1 & 1 & 9 \\
\hline Head and neck/thyroid & 0 & 3 & 3 & 0 & 2 & 1 & 2 & 1 & 12 \\
\hline Sarcoma & 3 & 2 & 4 & 0 & 2 & 1 & 1 & 1 & 14 \\
\hline Lymphoma & 2 & 2 & 0 & 3 & 3 & 1 & 1 & 1 & 13 \\
\hline Colorectal 1 & 3 & 2 & 2 & 0 & 2 & 2 & 1 & 1 & 13 \\
\hline Colorectal 2 & 2 & 2 & 2 & 0 & 1 & 1 & 1 & 1 & 10 \\
\hline Breast $^{a}$ & 3 & 1 & 2 & 0 & 2 & 3 & 1 & 1 & 13 \\
\hline Breast $^{\mathbf{b}}$ & 2 & 2 & 3 & 0 & 3 & 2 & 1 & 1 & 14 \\
\hline Urology $^{a}$ & 0 & 3 & 3 & 0 & 2 & 1 & 1 & 1 & 11 \\
\hline Urology $^{b}$ & 1 & 3 & 1 & 0 & 1 & 1 & 1 & 1 & 9 \\
\hline $\begin{array}{l}\text { Upper GI and } \\
\text { hepatobiliary tract }\end{array}$ & 3 & 2 & 4 & 0 & 2 & 2 & 1 & 1 & 15 \\
\hline $\begin{array}{l}\text { Abbreviations: CNS = clinica } \\
\text { a Chelsea branch. } \\
\text { b }_{\text {Sutton branch. }}\end{array}$ & & & & hary team meeting. & & & & & \\
\hline
\end{tabular}

Table 2. Number of new patients discussed in each tumour site-specific MDM, their cost per month and cost per case

\begin{tabular}{|l|c|c|c|}
\hline MDM & $\begin{array}{c}\text { No. of new patients } \\
\text { referred/discussed }\end{array}$ & $\begin{array}{c}\text { Cost per } \\
\text { MDM }(£)\end{array}$ & $\begin{array}{c}\text { Cost per } \\
\text { case }(£)\end{array}$ \\
\hline Gynaecology & $60(10.9 \%)$ & 8490 & 141 \\
\hline Renal & $13(2.4 \%)$ & 2192 & 168 \\
\hline Melanoma & $21(3.8 \%)$ & 3912 & 186 \\
\hline Lung & $31(5.6 \%)$ & 4047 & 130 \\
\hline Head and neck/thyroid & $56(10.2 \%)$ & 7124 & 127 \\
\hline Sarcoma & $66(12.0 \%)$ & 8079 & 122 \\
\hline Lymphoma & $22(4.0 \%)$ & 6930 & 315 \\
\hline Colorectal 1 & $10(1.8 \%)$ & 5161 & 516 \\
\hline Colorectal 2 & $18(3.3 \%)$ & 4824 & 268 \\
\hline Breast ${ }^{\text {a }}$ & $44(8.0 \%)$ & 5112 & 116 \\
\hline Breast ${ }^{\text {b }}$ & $73(13.2 \%)$ & 7656 & 105 \\
\hline Urology ${ }^{\text {a }}$ & $42(7.6 \%)$ & 4364 & 104 \\
\hline Urology ${ }^{\text {b }}$ & $41(7.4 \%)$ & 2917 & 71 \\
\hline $\begin{array}{l}\text { Upper gastrointestinal } \\
\text { and hepatobiliary tract }\end{array}$ & $54(9.8 \%)$ & 10050 & 186 \\
\hline Total & $551(100 \%)$ & 80858 & \\
\hline $\begin{array}{l}\text { Abbreviation: MDM }=\text { multidisciplinary team meeting. } \\
\text { a Chelsea branch. } \\
\text { b Sutton branch. }\end{array}$ & & & \\
\hline
\end{tabular}

MDMs, 9 patients at four MDMs and 2 patients at five MDMs. One patient was discussed at six MDMs. We looked in detail at 26 patients who were re-discussed on $\geqslant 3$ occasions and list the reasons for re-discussion in Table 3.

Delays in MDM decision making because of delays with pathology and/or radiology review were investigated and we found
Table 3. Reasons for multiple MDM re-discussions ( $\geqslant 3$ )

\begin{tabular}{|l|c|}
\hline Reason for re-discussion & Number \\
\hline Clinical trial & $6(18.2 \%)$ \\
\hline Radiology delay & $5(15.1 \%)$ \\
\hline Pathology delay & $12(36.4 \%)$ \\
\hline Complex case & $10(30.3 \%)$ \\
\hline Total & $\mathbf{3 3}$ \\
\hline \multicolumn{2}{|l}{ Abbreviation: MDM = multidisciplinary team meeting. } \\
\hline
\end{tabular}

that 62 patients $(12.7 \%)$ had a delay to the decision on their management for these reasons. Lack of radiology availability was the cause in 30 cases (48.4\%), a lack of pathology availability in 26 cases (41.9\%) and a lack of availability of both in six cases (9.7\%). These delays were caused by factors within our own institution on one occasion and because of delays in receiving material from other institutions on 61 occasions (98.4\%).

There were 48 instances (8.7\%) when subsequent treatment differed from that agreed at the MDM. The reason for these deviations are highlighted in Table 4.

In a separate review over subsequent months, we found that 29 consultants had clearly documented their opinion regarding the management/treatment plan for 81 patients before the MDM discussion. These 81 patients were presented at $10 \mathrm{MDMs}$ and there was only minimal discordance between the MDM decision and the one made by the consultant before the meeting. The consultant management plan matched that of the MDM consensus for $71(87.6 \%)$ patients. Ten (12.4\%) patients had different treatment suggested by the MDM with only four (4.9\%) major alterations to the consultants plan and six minor alterations.

The cost of each MDM ranged from $£ 2192$ to $£ 10050$ (median £5136) per month, with the total cost for all 14 MDMs in this 


\begin{tabular}{|c|c|}
\hline Reason for deviation in MDM treatment plan & Occurrences \\
\hline Consultant decision & $11(22.9 \%)$ \\
\hline Patient deterioration or comorbidities & $16(33.3 \%)$ \\
\hline Patient preference & $15(31.2 \%)$ \\
\hline Delay with pathology/radiology & $3(6.3 \%)$ \\
\hline New (re-staging) information & $3(6.3 \%)$ \\
\hline Total & $48(100 \%)$ \\
\hline
\end{tabular}

survey totalling $£ 80850$ per month (Table 1 ). The results of the more detailed cost analysis for the four larger MDMs can be seen in Table 5 and these ranged from $£ 14430$ to $£ 38327$ per month.

\section{DISCUSSION}

It has been shown that multidisciplinary-based care results in more robust decision making processes (Chang et al, 2001; Skinner et al, 2003; Stefoski Mikeljevic et al, 2003; Ingram et al, 2005), can improve survival (Junor et al, 1994; Birchall et al, 2004; Houssami and Sainsbury, 2006), shorten the time taken to accurately stage patients, (Davies et al, 2006) and reduce waiting times for treatment (Gabel et al, 1997). There is also evidence that the patient experience is improved with the use of MDMs (Murray et al, 2003). It has been estimated that $<20 \%$ of all patients with cancer in England were managed in the context of a specialist team 15 years ago, 10 years later that number had increased to $80 \%$ (Griffith and Turner, 2004; Fleissig et al, 2006). The multidisciplinary approach has also been promoted by health bodies in other countries including the USA (Chang, 1998) and Australia (Baume, 2002). Radiation oncology inquiry. A vision for radiotherapy. Canberra) and by cancer units in New Zealand (Stevens et al, 2012) and member states of the European union (Stalfors et al, 2005; Van Belle, 2008; Guillem et al, 2011; Mazzaferro and Majno, 2011). In the United Kingdom, the Cancer Reform Strategy (2007) emphasised that MDM working, as specified by NICE guidance, will remain the core model of cancer service delivery for hospitals in the future (Department of Health, 2000, 2004).

In our study, $97.1 \%$ of patients were treated following MDM discussion. A small proportion of patients were treated before MDM discussion for variety of reasons and these included: patients who were acutely unwell and required urgent intervention, patients who had been transferred from another hospital where treatment had already been instituted and some patients with prostate cancer who had already commenced neoadjuvant hormonal therapy in accordance our institution's Urology Unit policy.

The NHS Cancer plan (2000) also outlined the requirement for all patients to be treated within 1 month of diagnosis by 2005 (Department of Health, 2000). This target is not always met at our institution and reasons for this include late referral to the cancer centre. In addition, when patients are due to undergo major surgery they may require considerable time before fully informed consent is given. There can also be a particular issue with major surgery when comorbidities necessitate further investigations and treatment in order to optimise the patient's clinical status and fitness. An avoidable reason for delay is the lack of timely transfer of patient information and materials from referring hospitals. This problem particularly affects imaging and pathology transfer and may reflect our case mix as it is possible that the Royal Marsden

Table 5. Detailed MDM costings
\begin{tabular}{|l|c|}
\hline MDM & Cost (£ per month) \\
\hline Breast & 38327 \\
\hline Colorectal & 31309 \\
\hline Upper gastrointestinal & 17231 \\
\hline Gynaecology & 14430 \\
\hline Total & 101297 \\
\hline Abbreviation: MDM = multidisciplinary team meeting.
\end{tabular}

has more tertiary and quaternary referrals than other institutions, which could complicate the retrieval of pathology and imaging. The former can easily be solved by the use of electronic transfer technologies or even simply giving the patient a copy of their images on a disc, although encryption or incompatibility difficulties are sometimes encountered. It is our experience that some institutions both within the NHS and private sector appear reluctant to do this unless they receive payment. Such requests for remuneration and inefficient systems for data/material transfer within cancer networks are in our view, unjustified, inappropriate and indefensible. Patients have a right to access their own data and are entitled to a second opinion. Few would defend a clinician who levied a charge to write a referral letter for a second opinion so by the same token, there should be no financial penalty for the release of pathology or imaging material. These materials are an integral part of patient assessment in cancer medicine and the placing of financial and organisational barriers to their timely transfer is something that should concern the regulators of medical practice. This issue is becoming a serious clinical problem particularly in relation to the transfer of pathology blocks because of the increasing need for molecular profiling. Indeed, in some cancers this is already an absolute requirement before an optimal treatment plan can be formulated.

A high percentage (97.1\%) of MDM decisions were correctly and accurately documented. One of the reasons for this outcome is a process of strict review of the electronic patient record by secretarial staff and MDM coordinators following MDMs. There is subsequent communication with those responsible for documenting the decisions within $48 \mathrm{~h}$ of the meeting. The introduction of MDM proformas has also helped in this regard. Poor documentation, when it occurred, involved poor handwriting on the MDM proforma or ambiguous annotations, which gave no clear account of the MDM decision. Such ambiguities often occur as a result of there being more than one treatment option and can be resolved by the MDM lead clearly summarising complex cases at the end of the discussions.

A surprisingly high percentage of cases in this audit (41.2\%) were discussed more than once. This is time consuming, can cause patient anxiety and lead to delays in treatment. On the other hand, treatment decisions should not be rushed if quality is to be maintained. It was found that re-discussions occurred more often in those patients who were being treated in the context of a clinical trial as a consequence of the need for additional investigations to confirm eligibility. Other reasons included patients not being adequately worked up at initial presentation and here problems with the transfer of images and pathology material had a major role. Clinical teams should create clear processes for information gathering and perhaps develop criteria for the placing of a patient onto an MDM list.

Our study confirms that adherence to MDM decisions by health-care professionals occurs in the vast majority of patients. Deviation from the treatment pathway agreed upon at the MDM was often a consequence of patient preference, a change in the 
patient's general health or performance status, treatment limiting comorbidities not highlighted at the MDM, and occasionally the final decision of the treating consultant.

Ruhstaller et al (2006) suggested that decisions made at the MDM can be categorised into two groups. MDM decisions can be seen as recommendations to the treating physician or they can be seen as making the final decision. Historically, in the United Kingdom, MDMs were developed to stop practice that was not evidence-based and to create teams that were made up of cancer specialists from all relevant disciplines (Department of Health, 2000, 2004, Calman-Hine Report, 'Expert Advisory Group on Cancer, 1995 Calman-Hine Report, 'Expert Advisory Group on Cancer. A policy framework for commissioning cancer services: a report to the chief medical officers of England and Wales,' Department of Health, 1995). MDMs were to identify individuals who regularly practiced beyond acceptable parameters and they were to ensure such practices were discontinued (Patkar et al, 2011). MDMs should not and indeed cannot, dictate the treatment of every single cancer patient in an institution, rather they should ensure that most practice in a team occurs within the parameters set by the team, which in turn is informed by the literature. The high level of adherence to MDM consensus in our institution suggests that there is good agreement within our teams as to how patients should be managed.

The separate review of 81 patients revealed that there was a high level of concordance (87.6\%) between the consultant management plan set out before the MDM and that made subsequently by the MDM. The high degree of concordance between the consultant's view of management and the MDM consensus could be biased in that patients were selected based on the presence of a clearly documented consultant decision regarding the treatment pathway before MDM. This was possibly more likely for uncomplicated compared with more complex cases. Only four patients had major alterations in their management plan and these were all because of a change in histological diagnosis or radiological review. These anomalies would most likely have been highlighted and acted upon at the well-established team pathology and radiology meetings that also occur. It could be argued that the MDM had no direct role in this and such alterations could have been acted on without the input of a MDM. This result in particular calls into question the efficiency of the current process that dictates all new patients are discussed at a MDM. The cost of MDMs is considerable as shown by our data, which are possibly an underestimate anyway. All countries are examining their health-care systems for costeffectiveness and it would seem sensible that MDMs join the list of health-care processes that are currently under scrutiny.

Our data suggest that MDMs are time consuming, expensive and by any definition inefficient. An extrapolation of our data suggest that our institution is spending in the region of $£ 970296$ per year on our solid tumour and lymphoma MDMs. This figure rises to $£ 2745082$ per year if basic costings are re-estimated using the more detailed analysis we performed on the breast, upper gastrointestinal, lower gastrointestinal and gynaecological cancer MDMs, or $£ 415$ per new patient MDM discussion. The total spend on our MDMs equates approximately to the yearly NHS salaries of 50 Band Seven nurses or 20 consultants.

We need a discussion within oncology as to how we might rethink our MDM processes and practices. We should try and develop a system where complex and difficult cases are flagged for MDM discussion while routine treatment decisions are overseen by strict protocols and regular audits (Ruhstaller et al, 2006). There are of course additional benefits of the MDM other than the discussion relating to the management of individual patients. These include its role as an educational forum, a catalyst for ideas for research and audit, identification and verification of the suitability of patients for clinical trial entry (Bouvier et al, 2007) and a clinical audit and quality assurance tool. MDMs can also be very useful for team building and fostering a collegiate culture across disciplines. The benefits to individual MDM members in terms of improving working relationships, sharing of coordination and responsibility for patient care cannot be understated (Chirgwin et al, 2010). None of these important functions should be overlooked as they strengthen the ethos of good clinical governance (Scally and Donaldson, 1998). The challenge is how in these times of shrinking health-care resources we can streamline the MDM processes and improve efficiency without losing the considerable benefits associated with regular MDMs.

\section{ACKNOWLEDGEMENTS}

We would like to thank all our colleagues on our clinical units for all their support and help with this study and the ongoing support of the NIHR Biomedical Research Centre at the Royal Marsden NHS Trust and Institute of Cancer Research.

\section{CONFLICT OF INTEREST}

The authors declare no conflict of interest.

\section{AUTHOR CONTIBUTIONS}

PBD was principal investigator of the study. PBD, JIC and MEG contributed to study design. PBD, JIC, IL, US, MN and SF contributed to the acquisition of data. PBD, JIC and MEG contributed to the analysis and interpretation of the data. The report was written by PBD, with contributions from JIC and MEG. All authors contributed to the critical review and appraisal of the final manuscript.

\section{REFERENCES}

Baume P (2002) Radiation Oncology Inquiry. A Vision for Radiotherapy Canberra CoA.

Birchall M, Bailey D, King P (2004) Effect of process standards on survival of patients with head and neck cancer in the south and west of England. Br J Cancer 91(8): 1477-1481.

Bouvier AM, Bauvin E, Danzon A, Grosclaude P, Delafosse P, Buemi A, Tretarre B, Raverdy N, Maarouf N, Velten M, Launoy G, Faivre J (2007) Place of multidisciplinary consulting meetings and clinical trials in the management of colorectal cancer in France in 2000. Gastroenterol Clin Biol 31(3): 286-291.

Calman-Hine Report 'Expert Advisory Group on Cancer. A policy framework for commissioning cancer services: a report to the chief medical officers of England and Wales,' Department of Health (1995).

Chang AE (1998) Multidisciplinary cancer clinics: their time has come. J Surg Oncol 69(4): 203-205.

Chang JH, Vines E, Bertsch H, Fraker DL, Czerniecki BJ, Rosato EF, Lawton T, Conant EF, Orel SG, Schuchter L, Fox KR, Zieber N, Glick JH, Solin LJ (2001) The impact of a multidisciplinary breast cancer center on recommendations for patient management: the University of Pennsylvania experience. Cancer 91(7): 1231-1237.

Chirgwin J, Craike M, Gray C, Watty K, Mileshkin L, Livingston PM (2010) Does multidisciplinary care enhance the management of advanced breast cancer?: evaluation of advanced breast cancer multidisciplinary team meetings. J Oncol Pract 6(6): 294-300.

Davies AR, Deans DA, Penman I, Plevris JN, Fletcher J, Wall L, Phillips H, Gilmour H, Patel D, de Beaux A, Paterson-Brown S (2006) The multidisciplinary team meeting improves staging accuracy and treatment selection for gastro-esophageal cancer. Dis Esophagus 19(6): 496-503.

Department of Health (2000) The NHS cancer plan: a plan for investment a plan for reform. London: Department of Health. 
Department of Health (2004) Cancer reform strategy- The NHS Cancer Plan \& the New NHS: Department of Health.

Fleissig A, Jenkins V, Catt S, Fallowfield L (2006) Multidisciplinary teams in cancer care: are they effective in the UK? Lancet Oncol 7(11): 935-943.

Forrest LM, McMillan DC, McArdle CS, Dunlop DJ (2005) An evaluation of the impact of a multidisciplinary team, in a single centre, on treatment and survival in patients with inoperable non-small-cell lung cancer. Br J Cancer 93(9): 977-978.

Gabel M, Hilton NE, Nathanson SD (1997) Multidisciplinary breast cancer clinics. Do they work? Cancer 79(12): 2380-2384.

Griffith C, Turner J (2004) United Kingdom National Health Service, Cancer Services Collaborative 'Improvement Partnership', Redesign of Cancer Services: a National Approach. Eur J Surg Oncol 30(Suppl 1): 1-86.

Guillem P, Bolla M, Courby S, Descotes JL, Laramas M, Moro-Sibilot D (2011) [Multidisciplinary team meetings in cancerology: setting priorities for improvement]. Bull Cancer 98(9): 989-998.

Houssami N, Sainsbury R (2006) Breast cancer: multidisciplinary care and clinical outcomes. Eur J Cancer 42(15): 2480-2491.

Ingram DM, McEvoy SP, Byrne MJ, Fritschi L, Joseph DJ, Jamrozik K (2005) Surgical caseload and outcomes for women with invasive breast cancer treated in Western Australia. Breast 14(1): 11-17.

Junor EJ, Hole DJ, Gillis CR (1994) Management of ovarian cancer: referral to a multidisciplinary team matters. Br J Cancer 70(2): 363-370.

Mazzaferro V, Majno P (2011) Principles for the best multidisciplinary meetings. Lancet Oncol 12(4): 323-325.

Murray PV, O'Brien ME, Sayer R, Cooke N, Knowles G, Miller AC, Varney V, Rowell NP, Padhani AR, MacVicar D, Norton A, Ashley S, Smith IE (2003) The pathway study: results of a pilot feasibility study in patients suspected of having lung carcinoma investigated in a conventional chest clinic setting compared to a centralised two-stop pathway. Lung Cancer 42(3): 283-290.

NHS executive (1996) Guidance on commissioning cancer services: improving outcomes in breast cancer- the manual. Leeds: Department of Health.

NICE. Published cancer service guidance (2006) London: National Institute for Health and Clinical Excellence.
Patkar V, Acosta D, Davidson T, Jones A, Fox J, Keshtgar M (2011) Cancer multidisciplinary team meetings: evidence, challenges, and the role of clinical decision support technology. Int J Breast Cancer 2011: 831605.

Ruhstaller T, Roe H, Thurlimann B, Nicoll JJ (2006) The multidisciplinary meeting: an indispensable aid to communication between different specialities. Eur J Cancer 42(15): 2459-2462.

Scally G, Donaldson LJ (1998) The NHS's 50 anniversary. Clinical governance and the drive for quality improvement in the new NHS in England. BMJ 317(7150): 61-65.

Skinner KA, Helsper JT, Deapen D, Ye W, Sposto R (2003) Breast cancer: do specialists make a difference? Ann Surg Oncol 10(6): 606-615.

Stalfors J, Bjorholt I, Westin T (2005) A cost analysis of participation via personal attendance $v s$ telemedicine at a head and neck oncology multidisciplinary team meeting. J Telemed Telecare 11(4): 205-210.

Stefoski Mikeljevic J, Haward RA, Johnston C, Sainsbury R, Forman D (2003) Surgeon workload and survival from breast cancer. $\mathrm{Br} J$ Cancer 89(3): 487-491.

Stephens MR, Lewis WG, Brewster AE, Lord I, Blackshaw GR, Hodzovic I, Thomas GV, Roberts SA, Crosby TD, Gent C, Allison MC, Shute K (2006) Multidisciplinary team management is associated with improved outcomes after surgery for esophageal cancer. Dis Esophagus 19(3): 164-171.

Stevens G, Loh J, Kolbe J, Stevens W, Elder C (2012) Comparison of recommendations for radiotherapy from two contemporaneous thoracic multidisciplinary meeting formats: co-located and video conference. Intern Med J 42(11): 1213-1218.

Van Belle S (2008) How to implement the multidisciplinary approach in prostate cancer management: the Belgian model. BJU Int 101(Suppl 2): $2-4$.

This work is published under the standard license to publish agreement. After 12 months the work will become freely available and the license terms will switch to a Creative Commons AttributionNonCommercial-Share Alike 3.0 Unported License. 